\title{
ANOMALOUS FADING AND CRYSTALLINE STRUCTURE: STUDIES ON INDIVIDUAL CHONDRULES FROM THE SAME PARENT BODY
}

\author{
RABIUL HAQUE BISWAS and ASHOK KUMAR SINGHVI \\ Geosciences Division, Physical Research Laboratory, Ahmedabad 380009, India
}

Received 31 January 2013

Accepted 6 May 2013

\begin{abstract}
Plagioclase feldspar is the major luminescent mineral in meteorites. Thermoluminescence (TL) characteristics, peak temperature $\left(\mathrm{T}_{\mathrm{m}}\right)$, full width at half maximum (FWHM), ratio of high (HT) to low temperature (LT) peak, and TL sensitivity (TL/dose/mass) to an extent reflect degree of crystallinity of the mineral. The present study explores and establishes a correlation between quantum mechanical anomalous (athermal) fading and structural state by examining TL of individual chondrules. Chondrules were separated using freeze-thaw technique from a single fragment of Dhajala meteorite. The results show large variation in $\mathrm{T}_{\mathrm{m}}\left(155-230^{\circ} \mathrm{C}\right)$, FWHM $\left(80-210^{\circ} \mathrm{C}\right)$ and $\mathrm{HT} / \mathrm{LT}(0.07-$ 0.47 ) and seem to be positively correlated. TL sensitivity (ranging from 14 to 554 counts $/ \mathrm{s} / \mathrm{Gy} / \mathrm{mg}$ ) decreases with increasing $\mathrm{T}_{\mathrm{m}}$ and FWHM. Large variations in TL parameters (Tm, FWHM, HT/LT, and Sensitivty) suggest that individual chondrules had different degree of crystallization. Thermal annealing experiments suggest that comparatively ordered form of feldspar can be converted to a disordered form by annealing the sample at high temperatures $\left(1000^{\circ} \mathrm{C}\right)$ for long time $(10 \mathrm{hr})$ in vacuum ( 1 mbar pressure) condition and rapidly cooling it. Measured anomalous fading suggest that fading rate increases as the crystal form changes from an ordered state to a disordered state. However, the fading rate becomes nearly negligible for the most disordered feldspars.
\end{abstract}

Keywords: TL of chondrules, anomalous fading, degree of crystallinity, thermal metamorphism, thermal annealing.

\section{INTRODUCTION}

The natural and laboratory induced thermoluminescence (TL) of meteorites have been extensively used to inform on the meteorite properties and several planetary parameters. For example, the natural TL (NTL) of meteorites provides information on the perihelion of the meteoroid orbit (Melcher, 1981); terrestrial age (Sears and Durrani, 1980) and possible estimation of cosmic ray exposure age (Biswas et al., 2011). The laboratory in-

Corresponding author: R.H. Biswas

e-mail: biswasrabiul@gmail.com duced TL, on the other hand has provided a way for detailed classification of meteorites (Sears et al., 1980).

Applications of luminescence to the estimation of terrestrial ages have been somewhat limited due the anomalous (athermal) loss of luminescence signal. Anomalous fading was first observed by Garlick and Robinson (1972) in lunar samples and later by Wintle (1973) in volcanic feldspars. This was explained as non-radiative quantum mechanical tunnelling of charges (Visocekas, 1985). More recent studies suggest that the trapped charges quantum mechanically tunnel from the ground state of the trap to the recombination centre (Poolton et al., 2002a; Poolton et al., 2002b). Despite the recent advance in the understanding of anomalous fading, the 
relationships of fading rate with lattice structure, chemical composition and the activation energies are not clear, and thus the fact that different grains from feldspars of the same provenance display different luminescence behaviour, needed elucidation (Huntley and Lamothe, 2001; Huntley and Lian, 2006; Jaek et al., 2007).

In Shergottites (of different origin and history), that comprise feldspar as the most common luminescent mineral, Hasan et al. (1986) observed that anomalous fading occurred in only those meteorites in which plagioclase was in a low-temperature ordered form. They generalized that feldspars with lower degree of thermal metamorphism (petrologic type 3.3-3.5) exhibited anomalous fading and feldspar with higher degree of metamorphism (type 3.6 and above) did not exhibit fading. Later, Tyler and McKeever (1988) reported that both the low- and the high-temperature form of oligoclase exhibited fading. Visocekas (2002) suggested that for terrestrial feldspar, only disordered one showed fading and ordered feldspar gave a stable luminescence signal. Thus, the basic question of elucidation of the state of lattice, when a feldspar crystal becomes prone to anomalous fading still remains unresolved. In the present study we explored a near ideal possibility to establish the correlation between anomalous fading and structural state by measuring fading rate of individual grains from same provenance and composition but with different degree of crystallinity.

Towards this a comparison of the luminescence properties of individual chondrules from the same meteorite fragment (Dhajala meteorite; type 3.8) was attempted. Chondrules are sub millimetre to a millimetre sized spherical objects comprising silicate such as olivine and pyroxenes and these are surrounded by mesostasis which in type 3 ordinary chondrites generally consist of feldspathic glass, either glassy or crystalline (Huss et al., 2006; Sears et al., 1984). Although the exact mechanism of their formation is not understood, it is suggested that chondrules are formed by flash heating and cooling (Zanda, 2004) and that they were heated to about 1500$1600^{\circ} \mathrm{C}$ and cooled at rate ranging from 10 to $1000^{\circ} \mathrm{C} / \mathrm{h}$ (Yu and Hewins, 1998).

It has been suggested that TL parameters such as temperature at which glow peak is maximum $\left(\mathrm{T}_{\mathrm{m}}\right)$, full width at half maximum (FWHM), and sensitivity (TL/unit dose/unit mass) are related to the degree of crystallinity of the mineral (Sears, 1988). Sears et al. (1984) separated 58 chondrules from Dhajala meteorite and found a large variation in $\mathrm{T}_{\mathrm{m}}\left(\sim 125-225^{\circ} \mathrm{C}\right), \mathrm{FWHM}$ $\left(\sim 55-190^{\circ} \mathrm{C}\right)$ and sensitivity $(0.002-0.12$ of the bulk sensitivity $=1)$. In that study, the TL of chondrules was measured without any optical filter, allowing whole TL emission limited only by the photomultiplier response. The present work extends this study by examining 17 chondrules separated from Dhajala meteorite and measuring their TL characteristics ( $\mathrm{T}_{\mathrm{m}}, \mathrm{FWHM}$ and sensitivity), constraining the TL emission in violet-blue $(395 \pm 30 \mathrm{~nm})$ region, the major TL emission band, and additionally conducting measurements on the anomalous fading for each of these chondrules.

\section{EXPERIMENTAL DETAILS}

The chondrules were separated from the matrix using freeze-thaw technique. The bulk sample was repeatedly recycled between liquid nitrogen temperature and room temperature in an $800 \mathrm{~W}$ ultrasonic bath. After around 50 cycles, about a gram of chondrule and matrix were recovered. The samples were then sieved to $300-1000 \mu \mathrm{m}$ grain fractions and the chondrules were manually picked under an optical microscope. Chondrules which had adherent matrix were not used. The separated chondrules were again cleaned in ultrasonic bath to remove any residual grains from matrix adhering to the chondrule surface. Individual chondrules were then mounted on stainless steel aliquots using silkospray. The weight of each chondrule was computed by measuring its dimension using an optical microscope, and assuming it to be an ellipsoid with a density of $3.4 \mathrm{~g} / \mathrm{cm}^{3}$.

The TL measurements were made using a Risø TL/OSL reader (TL/OSL DA-20; Bøtter-Jensen et al., 2010). The detection optics comprised a Thorn-EMI 9235 QA photomultiplier tube coupled to Corning 7-59 and BG-39 filter combination (transmission $395 \pm 30 \mathrm{~nm}$ ). The system had on-plate ${ }^{90} \mathrm{Sr} /{ }^{90} \mathrm{Y}$ beta irradiator. A linear heating rate of $2^{\circ} \mathrm{C} / \mathrm{s}$ under constant flow of ultrapure nitrogen was used.

\section{RESULTS}

\section{TL characteristics}

The chondrules were heated to $500^{\circ} \mathrm{C}$ to record the natural TL signal, and then a 100 Gy beta dose was given to each followed by $12 \mathrm{~h}$ storage at room temperature, and a TL glow up to $500^{\circ} \mathrm{C}$ was measured. The background was then recorded for each and subtracted. The laboratory dosed TL glow curves of chondrules had two glow peaks, i.e. low (LT) and high temperature (HT) peaks (Fig. 1a). The chondrules with low sensitivity had significant fluctuations due to dark noise being a significant component in the TL glow curves, and hence these were smoothed using 5 point running average to identify the exact peak position and to calculate FWHM accurately (inset of Fig. 1a). The peak temperature $\left(\mathrm{T}_{\mathrm{m}}\right)$ of the LT varied from $155-230^{\circ} \mathrm{C}$ between chondrules and the $\mathrm{T}_{\mathrm{m}}$ of HT occurred in the range $\sim 400-450^{\circ} \mathrm{C}$. The FWHM of LT ranged from $80-210^{\circ} \mathrm{C}$ and that of HT was difficult to estimate because of contribution of the high temperature region of LT to HT. The peak height ratio of HT to LT varied from $0.07-0.47$. The TL sensitivity, calculated by taking peak height of LT, varied from 14-554 counts/s/Gy/mg (Table 1), and the maximum TL sensitivity was $\sim 40$ times that of the least sensitive chondrule. Table 1 provides the experimental data. 

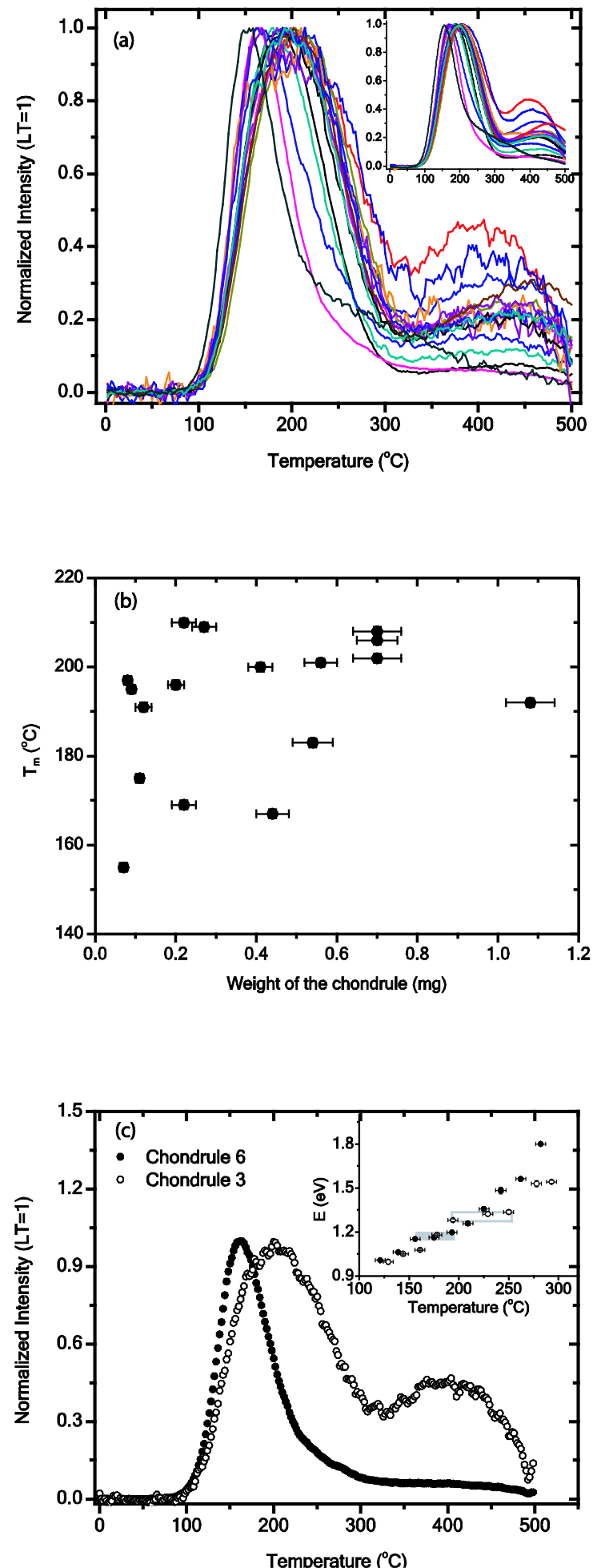

Fig. 1. a) The normalized ( $L T=1) T L$ glow curves of chondrules of 17 chondrules. The inset of the figure shows a smoothed curve obtained by taking running average, b) variation of peak temperature $\left(T_{m}\right)$ with mass (size) of the chondrules, c) the normalized TL glow curves of two extreme chondrules, Chondrule 6 (maximum sensitivity) and Chondrule 3 (minimum sensitivity). The insets of the figure shows trap depth distributions of the two chondrules at different temperature of the glow peak and the bars indicate distinctive traps at $\sim 1.17$ and $\sim 1.31 \mathrm{eV}$ for chondrule 6 and 3 respectively.
The TL glow curves were measured with a heating rate of $2{ }^{\circ} \mathrm{C} / \mathrm{s}$ under constant nitrogen flow and it was reasonably assumed that thermal lag even for larger grains was not an issue. To further examine this assumption, $\mathrm{T}_{\mathrm{m}}$ of LT of all chondrules were plotted against their computed masses (Fig. 1b). The random distribution of the points suggested that size dependent thermal lag was not a matter of concern.

The normalized TL glow curves of two extreme chondrules, Chondrule 6 (maximum sensitivity) and Chondrule 3 (minimum sensitivity) were then compared (Fig. 1c). TL of both the chondrules had LT and HT but their TL parameters ( $T_{m}, F W H M, H T / L T$ and sensitivity) were different. To know further characteristics of traps, trap depth distribution of the two chondrules were calculated using the initial rise method (Randall and Wilkinson, 1945). The trap depth of the Chondrule 6 (higher sensitivity) vary from 1.0 to $1.8 \mathrm{eV}$ and for Chondrule 3 (lower sensitivity) it vary from 1.0 to $1.6 \mathrm{eV}$ (inset of Fig. 1c). Although they have nearly same range, the trap depth distribution patterns are different. A clear distinct trap, where the trap depth distribution is parallel to temperature axis, is observed for both the chondrules, but the values are somewhat different; for Chondrule 6 it is $\sim 1.17 \mathrm{eV}$ whereas for chondrule 3 it is $1.31 \mathrm{eV}$. These traps appear in the temperature ranges of $\sim 156-193^{\circ} \mathrm{C}$ and $\sim 194-250^{\circ} \mathrm{C}$ respectively and correspond to the two $\mathrm{T}_{\mathrm{m}}$ (LT peak), $167^{\circ} \mathrm{C}$ and $202^{\circ} \mathrm{C}$ of the two respective chondrules. Considering the fact that TL of chondrule arises from feldspar mineral in an identical detection window, it can be plausibly suggested that the variation in TL parameters is due to different physical environment of the same defect.

\section{Degree of crystallinity and TL parameters}

Mutual correlation between TL parameters $\left(\mathrm{T}_{\mathrm{m}}\right.$, FWHM, HT/LT, sensitivity) of LT peak was explored for clues to reason for differences between chondrules. A large variation in $\mathrm{T}_{\mathrm{m}}\left(155-229^{\circ} \mathrm{C}\right)$, FWHM $\left(80-210^{\circ} \mathrm{C}\right)$, HT/LT (0.07-0.47) and sensitivity (14-554 count/s/Gy/mg) is seen and these parameters are correlated. The FWHM vs. $\mathrm{T}_{\mathrm{m}}$ (Fig. 2a), HT/LT vs. $\mathrm{T}_{\mathrm{m}}$ (Fig. 2b) and HT/LT vs. FWHM (Fig. 2c) plots, depict some correlations. Although the data are scattered, an increasing correlation is discernible. Figs. 2a and 2c show clear increasing trend, whereas the Fig. 2b shows larger scatter in the data and more like a cluster structure, still do discern an increasing trend.

The sensitivities of individual chondrules decrease with an increase of $T_{m}$ and FWHM (Figs. 3a and 3b). The sensitivities are presented in $\log _{10}$ scale. A similar trend between sensitivity, $\mathrm{T}_{\mathrm{m}}$ and FWHM was observed by Sears et al. (1984).

Keck et al. (1986) used laboratory annealing experiment to suggest that $\mathrm{T}_{\mathrm{m}}$ and FWHM increase if the crystallinity decreases. Since the parameter HT/LT follows similar trend as $T_{m}$ and FWHM, it can be implicitly sug- 
Table 1. List of different measured quantities, like mass, peak temperature, FWHM, peak ratio HT/LT, sensitivity and fading, for 17 chondrules. The error in masses were calculated by propagating uncertainty in the measurement of dimension using optical microscope and for peak temperature $\pm 1^{\circ} \mathrm{C}$ and for $\mathrm{FWHM} \pm 2^{\circ} \mathrm{C}$ error was considered. All TL parameters mentioned here are for $L T$ peak.

\begin{tabular}{|c|c|c|c|c|c|c|}
\hline Chondrule & Mass (mg) & $\mathrm{T}_{\mathrm{m}}\left({ }^{\circ} \mathrm{C}\right)$ & FWHM $\left({ }^{\circ} \mathrm{C}\right)$ & $(\mathrm{HT} / \mathrm{LT}) \times 10$ & Sensitivity & Fading (\%) \\
\hline 2 & $1.08 \pm 0.06$ & 192 & 106 & $0.79 \pm 0.02$ & $146 \pm 9$ & $19.1 \pm 4.1$ \\
\hline 3 & $0.7 \pm 0.06$ & 202 & 145 & $4.73 \pm 0.22$ & $22 \pm 2$ & $5 \pm 0.5$ \\
\hline 4 & $0.7 \pm 0.05$ & 206 & 128 & $3.3 \pm 0.13$ & $36 \pm 3$ & $4.9 \pm 0.4$ \\
\hline 5 & $0.54 \pm 0.05$ & 183 & 103 & $1.19 \pm 0.05$ & $89 \pm 8$ & $13.7 \pm 1.2$ \\
\hline 6 & $0.44 \pm 0.04$ & 167 & 80 & $0.64 \pm 0.02$ & $544 \pm 49$ & $5.2 \pm 0.3$ \\
\hline 7 & $0.27 \pm 0.03$ & 209 & 128 & $2.5 \pm 0.08$ & $168 \pm 19$ & $1 \pm 0.1$ \\
\hline 8 & $0.7 \pm 0.06$ & 208 & 152 & $4.05 \pm 0.24$ & $14 \pm 1$ & $3.8 \pm 0.5$ \\
\hline 10 & $0.41 \pm 0.03$ & 200 & 125 & $2.39 \pm 0.12$ & $56 \pm 5$ & $1.5 \pm 0.1$ \\
\hline 12 & $0.22 \pm 0.03$ & 169 & 99 & $1.62 \pm 0.08$ & $169 \pm 20$ & $10.2 \pm 1.1$ \\
\hline 13 & $0.22 \pm 0.03$ & 210 & 144 & $2.67 \pm 0.24$ & $34 \pm 4$ & $1.8 \pm 0.4$ \\
\hline 14 & $0.11 \pm 0.01$ & 175 & 138 & $2.43 \pm 0.21$ & $75 \pm 11$ & $4.3 \pm 1$ \\
\hline 15 & $0.2 \pm 0.02$ & 196 & 124 & $2.62 \pm 0.1$ & $160 \pm 20$ & $4.6 \pm 0.4$ \\
\hline 16 & $0.12 \pm 0.02$ & 191 & 120 & $2.19 \pm 0.1$ & $225 \pm 33$ & $0 \pm 0$ \\
\hline 17 & $0.56 \pm 0.04$ & 201 & 121 & $3.07 \pm 0.07$ & $130 \pm 9$ & $5.7 \pm 0.4$ \\
\hline 18 & $0.08 \pm 0.01$ & 197 & 135 & $2.34 \pm 0.14$ & $209 \pm 35$ & $6.1 \pm 0.7$ \\
\hline 19 & $0.09 \pm 0.01$ & 195 & 121 & $2.26 \pm 0.11$ & $310 \pm 47$ & $3.7 \pm 0.4$ \\
\hline 20 & $0.07 \pm 0.01$ & 155 & 81 & $1.28 \pm 0.07$ & $465 \pm 82$ & $4.2 \pm 0.5$ \\
\hline
\end{tabular}

gested that the ratio HT/LT should also be correlated with crystallinity. Assuming this to be so, chondrules with lower $\mathrm{T}_{\mathrm{m}}, \mathrm{FWHM}$ and HT/LT, and higher sensitivity should have comparatively a more ordered form of feldspar glass, and chondrules with higher $\mathrm{T}_{\mathrm{m}}$, FWHM and HT/LT, and lower sensitivity should comprise more disordered form of feldspar glass. These results suggest that within a small piece of meteorite, individual chondrules have different degree of crystallinity.

\section{Fading and crystallinity}

Anomalous fading rate of individual chondrules was calculated by measuring instant TL signal $\left(\mathrm{TL}_{1}\right)$ immediately after artificial irradiation (100 Gy) and after storage for 43 days $\left(\mathrm{TL}_{2}\right)$ at room temperature $\left(21^{\circ} \mathrm{C}\right)$. TL glow curves with and without fading are shown in Fig. 4a. Given that the sensitivity can change due to heating associated with a TL glow curve recording, sensitivity correction for the TL signal was made using a test dose (100 Gy) TL following each TL measurements. The test dose signal was used to normalize the corresponding TL signals. The ratio of sensitivity corrected $\mathrm{TL}_{2}$ to $\mathrm{TL}_{1}$ in the temperature region $300-400^{\circ} \mathrm{C}$ (inset of Fig. 4a), where the signals are thermally stable and plateaus of $\mathrm{TL}_{2} / \mathrm{TL}_{1}$ with temperature, was used for the estimation of fading for 43 days.

The fading rates of all the chondrules are plotted as a function of $\mathrm{T}_{\mathrm{m}}$ (Fig. 4b) and FWHM (Fig. 4c). The results show two clusters, A and B. In region A (lower $\mathrm{T}_{\mathrm{m}}$ and FWHM) fading rate increases with $\mathrm{T}_{\mathrm{m}}$ and FWHM, whereas in region B (higher $T_{m}$ and FWHM) fading rate is independent of $T_{m}$ and FWHM and the values are near zero. In other word the fading rate initially increases with increasing the $\mathrm{T}_{\mathrm{m}}$ and FWHM and then reduces to a lower value beyond $\mathrm{T}_{\mathrm{m}}=\sim 190^{\circ} \mathrm{C}$ and $\mathrm{FWHM}=110^{\circ} \mathrm{C}$.
In region $\mathrm{A}$, where the chondrules are in comparatively ordered state (lower $\mathrm{T}_{\mathrm{m}}$ and FWHM, and higher sensitivity), the fading rate increases with decreasing the degree of crystallinity. And in region B, where the chondrules are in comparatively disordered state (higher $\mathrm{T}_{\mathrm{m}}$ and FWHM, and lower sensitivity), the fading rate is negligible. Thus disordered form of feldspathic glass shows reduced fading. Short range order and low sensitivity in region B suggest that the volume density of traps is low and thereby the probability of overlap and tunnelling is also low, leading to low athermal fading.

\section{Effect of thermal annealing}

Two chondrules, Chondrule 6 (most ordered) and Chondrule 3 (most disordered), were annealed under identical conditions, at $1000^{\circ} \mathrm{C}$ under $1 \mathrm{mbar}$ pressure for $10 \mathrm{~h}$ and then allowed to rapidly cool to room temperature by leaving the sealed capsules containing the samples in air. The TL parameters $\left(\mathrm{T}_{\mathrm{m}}, \mathrm{FWHM}, \mathrm{HT} / \mathrm{LT}\right.$, and sensitivity), before and after the thermal cycling, were then compared (Table 2). The TL glow curves, before and after annealing are shown in Fig. 5.

For Chondrule 6, due to thermal treatment, $\mathrm{T}_{\mathrm{m}}$ marginally increased by $3^{\circ} \mathrm{C}$, the FWHM increased by $86^{\circ} \mathrm{C}$ and the peak became skewed towards high temperature, the peak ratio HT/LT increased by factor of 4 , and the sensitivity decreased by a factor of 6 . For Chondrule 3 , the change in TL parameters (particularly FWHM, $\mathrm{HT} / \mathrm{LT}$ and sensitivity) was minimal, $\mathrm{T}_{\mathrm{m}}$ increased by $5^{\circ} \mathrm{C}$, the FWHM increased by $2^{\circ} \mathrm{C}$, the peak ratio HT/LT increased by factor of 3 , and the sensitivity decreased by a factor of 3 (Table 2). These results suggest that the annealing (temperature and cooling rate) change the crystal properties and the change is more for the chondrule with higher order. 

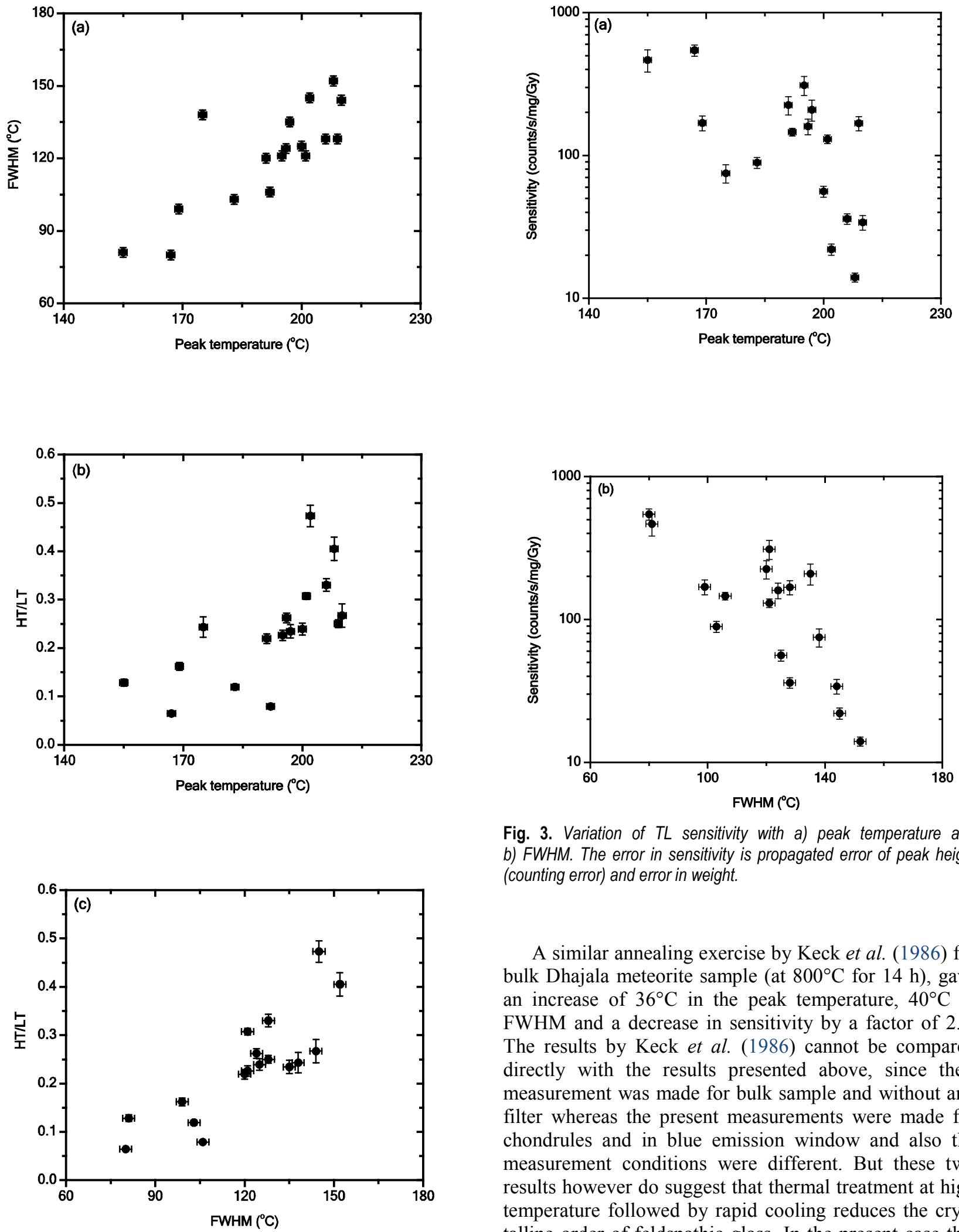

Fig. 2. Relationship between TL parameters (Tm, FWHM, and peak ratio $H T / L T$ ). a) FWHM vs. peak temperature, b) $H T / L T$ vs. FWHM, c) $H T / L T$ vs. Peak temperature. For peak temperature $\pm 1^{\circ} \mathrm{C}$ and for FWHM $\pm 2{ }^{\circ} \mathrm{C}$ error was considered. The error for $H T / L T$ is propagated counting statistics error of two peak height.

A similar annealing exercise by Keck et al. (1986) for bulk Dhajala meteorite sample (at $800^{\circ} \mathrm{C}$ for $14 \mathrm{~h}$ ), gave an increase of $36^{\circ} \mathrm{C}$ in the peak temperature, $40^{\circ} \mathrm{C}$ in FWHM and a decrease in sensitivity by a factor of 2.5 . The results by Keck et al. (1986) cannot be compared directly with the results presented above, since their measurement was made for bulk sample and without any filter whereas the present measurements were made for chondrules and in blue emission window and also the measurement conditions were different. But these two results however do suggest that thermal treatment at high temperature followed by rapid cooling reduces the crystalline order of feldspathic glass. In the present case this change was discernible. However the activation energy distribution of Chondrule 6 (most ordered) did not change due to thermal annealing (Fig. 6). 

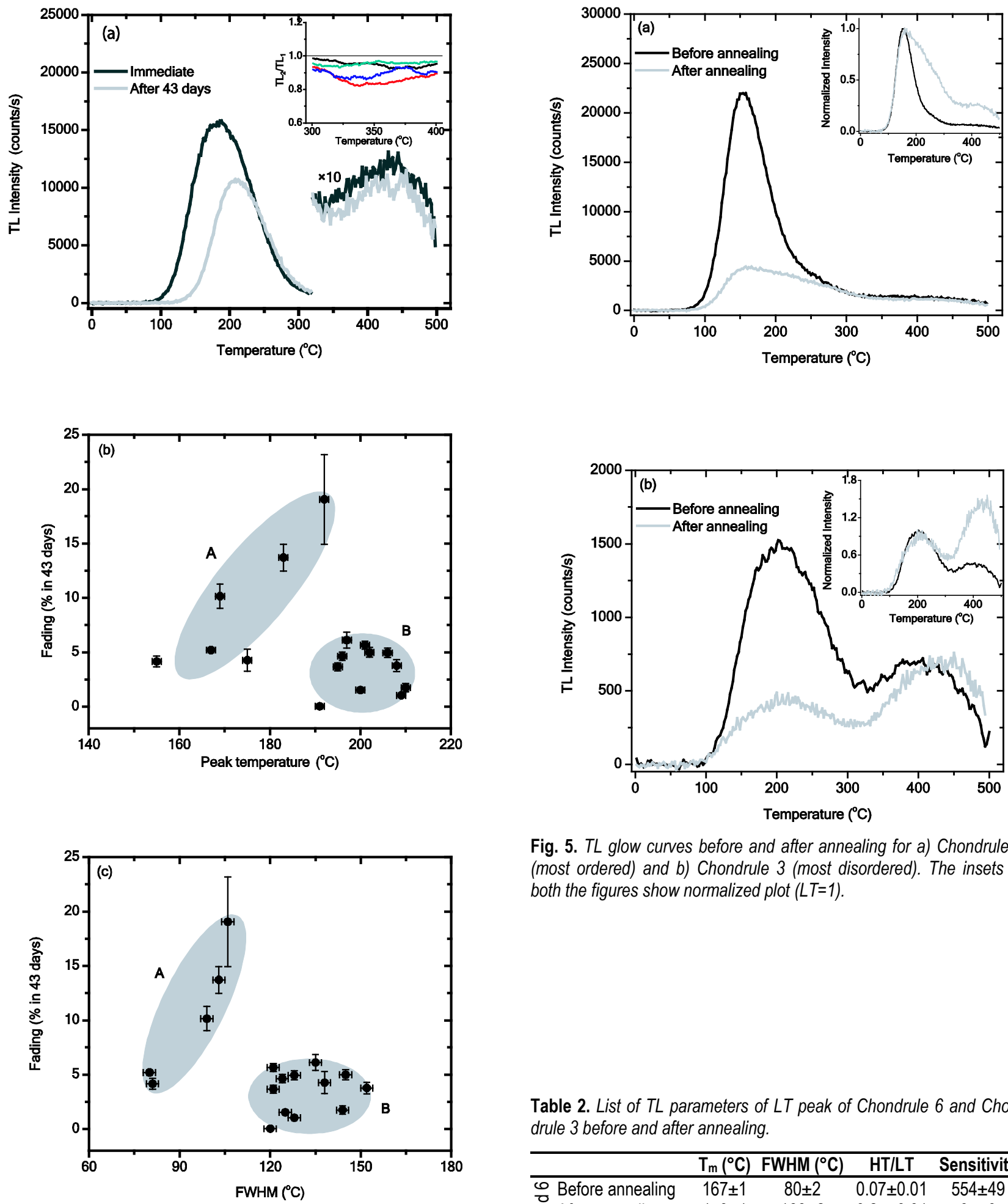

Fig. 4. a) $T L$ glow curves of the $100 \mathrm{~Gy}$ dosed chondrule (Chondrule 2) with (43 days storage after irradiation) and without (immediate after irradiation) fading. The high temperature parts of the $T L$ glow curve $\left(300-500^{\circ} \mathrm{C}\right)$ are blown up by multiplying a factor 10 to make it visible. The inset of the figure shows the ratio of $T L_{2}$ (with fading) to $T L_{1}$ (without fading) with glow curve temperature in the range $300-400^{\circ} \mathrm{C}$; $b, c)$ fading in $\%$ for 43 days vs. peak temperature and FWHM respectively. Two clear regions, $A$ and $B$, are marked in both the figures.

Fig. 5. TL glow curves before and after annealing for a) Chondrule 6 (most ordered) and b) Chondrule 3 (most disordered). The insets of both the figures show normalized plot ( $L T=1)$.

Table 2. List of TL parameters of $L T$ peak of Chondrule 6 and Chondrule 3 before and after annealing.

\begin{tabular}{|c|c|c|c|c|}
\hline & $\mathrm{T}_{\mathrm{m}}\left({ }^{\circ} \mathrm{C}\right)$ & FWHM $\left({ }^{\circ} \mathrm{C}\right)$ & HT/LT & Sensitivity \\
\hline$\overline{\text { Before annealing }}$ & $167 \pm 1$ & $80 \pm 2$ & $0.07 \pm 0.01$ & $554 \pm 49$ \\
\hline of After annealing & $170 \pm 1$ & $166 \pm 2$ & $0.27 \pm 0.01$ & $95 \pm 9$ \\
\hline こ Change & +3 & +86 & $\times 4$ & 16 \\
\hline m Before annealing & $202 \pm 1$ & $145 \pm 2$ & $0.47 \pm 0.02$ & $22 \pm 2$ \\
\hline O After annealing & $207 \pm 1^{*}$ & $147 \pm 2^{*}$ & $1.54 \pm 0.09$ & $7 \pm 1$ \\
\hline ভ Change & +5 & +2 & $\times 3$ & 13 \\
\hline
\end{tabular}

*Due to significant overlap between the LT and HT peak, the two peaks were de-convoluted using computerized curve de-convolution (CCD; Afouxenidis et al. 2012) and the parameters were calculated. 


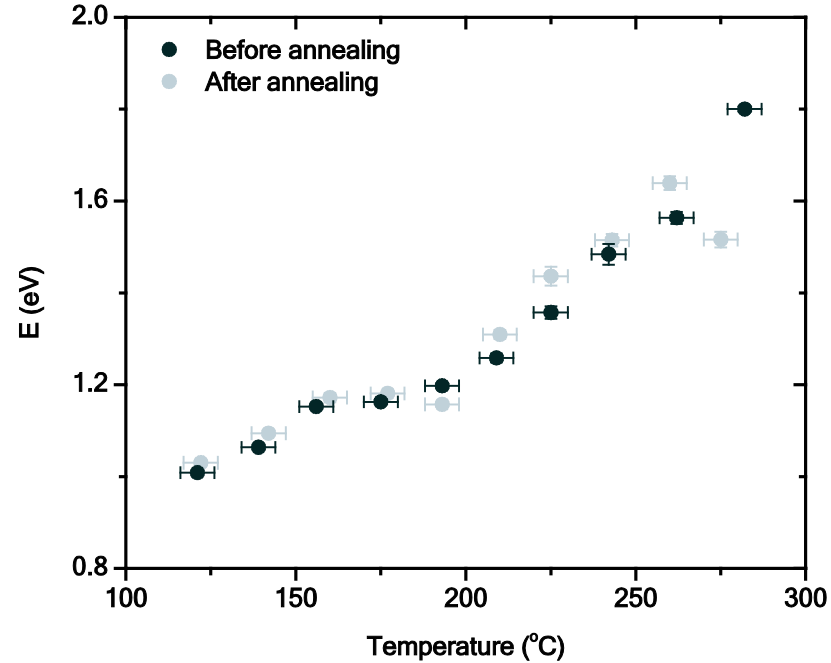

Fig. 6. Plot of thermal activation energy at different temperature of the glow curves of Chondrule 6 before and after annealing.

\section{DISCUSSION}

\section{Variation of TL parameters from chondrule to chon- drule}

The present study indicates that within a single meteorite (Dhajala) body, individual chondrules have a range of TL parameters ( $\mathrm{T}_{\mathrm{m}}, \mathrm{FWHM}, \mathrm{HT} / \mathrm{LT}$ and sensitivity) and as a first order approximation this can be attributed to variation in the crystallinity. Two possible reasons for such variations are: 1) the individual chondrules experienced different degrees of in situ thermal metamorphism after accretion in to parent body, and 2) chondrules formed under different crystallization temperature and/or experienced different cooling rate during crystallization, prior to their accretion in the parent body.

From the point of view of TL, the following is to be noted. The chondrules were collected from a meteorite piece of dimension $\sim 1 \mathrm{~cm}^{3}$ and within such a small volume element heterogeneity in thermal metamorphism is unlikely. Further, the variation of TL sensitivity with $T_{m}$ and FWHM for chondrules is opposite to those present in such plot for bulk chondrites (Sears and Weeks, 1983; Sears et al., 1984). Studies on different bulk chondrites by Sears and Weeks (1983) show that the TL sensitivity of chondrite increases with $T_{m}$ and FWHM due to different degree of thermal metamorphism, occurs at temperatures $\sim 400-600^{\circ} \mathrm{C}$ (Dodd, 1981). The present study and earlier studies by Sears et al. (1984) on individual chondrules show a decreasing trend of TL sensitivity with $T_{m}$ and FWHM. These enable a logical inference that variation of TL parameters from chondrule to chondrule is not due to thermal metamorphism but due to variation in crystallization temperature or cooling rate during formation from a high temperature melt.

\section{Variation of anomalous fading rate with degree of crystallinity}

As the $\mathrm{T}_{\mathrm{m}}$ and FWHM increase or the crystal becomes more amorphous, the anomalous fading rate first increase and then suddenly reduces to near zero value. This result accords with Hasan et al. (1986), where they concluded that ordered form of meteorite feldspar exhibited fading whereas disordered form of meteorite feldspar did not exhibit fading. A nearly similar study but on different type of sample by Berger (1985), showed that $100 \%$ clear volcanic glass, with a disordered lattice, did not show any anomalous fading.

Dependency of anomalous fading rate on crystallinity (section 3) suggests that the temperature during chondrule formation decides the crystallinity and anomalous fading rate. Higher cooling rate during crystallization leads to higher degree of amorphous phase. The plot of anomalous fading rate with $\mathrm{T}_{\mathrm{m}}$ and FWHM (first increase and then reduction to near zero value) suggests that beyond certain annealing condition (temperature and cooling rate) a definite phase occurs and the anomalous fading rate of the mineral becomes nearly zero. And before that critical annealing condition, anomalous fading increases as the crystal moves towards amorphous side. A question that still persists is: why fading with crystallinity does not follow a monotonic trend, rather the fading parameter suddenly drops down to near zero value beyond certain degree of crystallinity? An incremental annealing condition (temperature and cooling rate) on easily available terrestrial feldspar coupled with X-ray diffraction (XRD) analysis on single grain may elucidate the processes better.

\section{SUMMARY}

1) In a single meteorite fragment (Dhajala) different chondrules have different TL parameters $\left(T_{m}\right.$, FWHM, HT/LT and sensitivity),

2) $T_{m}$, FWHM and HT/LT are positively correlated, whereas sensitivity is negatively correlated with these parameters.

3) Chondrule with lower $T_{m}$, FWHM and HT/LT, and higher sensitivity have higher degree of crystallinity and vice versa.

4) As the crystallinity of the chondrules (feldspar) decreases, the anomalous fading rate first increases and then suddenly drops down to a near zero value.

5) The most disordered chondrules show negligible fading.

\section{ACKNOWLEDGEMENT}

We thank to Prof. J.N. Goswami for the Dhajala meteorite samples. 


\section{REFERENCES}

Afouxenidis D, Polymeris GS, Tsirliganis NC and Kitis G, 2012. Computerised curve deconvolution of TL/OSL curves using a popular spreadsheet program. Radiation Protection Dosimetry 149(4): 363-370, DOI 10.1093/rpd/ncr315.

Berger GW, 1985. Thermoluminescence dating of volcanic ash. Journal of Volcanology and Geothermal Research 25(3-4): 333-347, DOI 10.1016/0377-0273(85)90020-4.

Biswas RH, Morthekai P, Gartia RK, Chawla S and Singhvi AK, 2011. Thermoluminescence of the meteorite interior: A possible tool for the estimation of cosmic ray exposure ages. Earth and Planetary Science Letters 304(1-2): 36-44, DOI 10.1016/j.eps1.2011.01.012.

Bøtter-Jensen L, Thomsen KJ and Jain M, 2010. Review of optically stimulated luminescence (OSL) instrumental developments for retrospective dosimetry. Radiation Measurements 45(3-6): 253257, DOI 10.1016/j.radmeas.2009.11.030.

Dodd RT, 1981. Meteorites - A Petrologic-Chemical Synthesis, Cambridge, New York.

Garlick GFJ and Robinson JE, 1972. The thermoluminescence of lunar sample. In the Moon (Edited by Runcorn SK and Urrey H). International astronomical unit: 324-329.

Hasan FA, Keck BD, Hartmetz C and Sears DWG, 1986. Anomalous fading of thermoluminescence in meteorites. Journal of Luminescence 34(6): 327-335, DOI 10.1016/0022-2313(86)900761.

Huntley DJ and Lamothe M, 2001. Ubiquity of anomalous fading in Kfeldspars and the measurement and correction for it in optical dating. Canadian Journal of Earth Sciences 38(7): 1093-1106, DOI $10.1139 / \mathrm{e} 01-013$.

Huntley DJ and Lian OB, 2006. Some observations on tunnelling of trapped electrons in feldspars and their implications for optical dating. Quaternary Science Reviews 25(19-20): 2503-2512, DOI 10.1016/j.quascirev.2005.05.011.

Huss GR, Rubin AE and Grossman JN, 2006. Thermal Metamorphism in Chondrites. Meteorites and the Early Solar System II (Edited by Lauretta DS and McSween H Y Jr.). University of Arizona Press, Tucson: 567-586.

Jaek I, Molodkov A and Vasilchenko V, 2007. Possible reasons for anomalous fading in alkali feldspars used for luminescence dating of quaternary deposits. Estonian Journal of Earth Sciences 56(3): 167-178.

Keck BD, Kyle Guimon R and Sears DWG, 1986. Chemical and physical studies of type 3 chondrites, VII. Annealing studies of the Dhajala H3.8 chondrite and the thermal history of chondrules and chondrites. Earth and Planetary Science Letters 77(3-4): 419-427, DOI 10.1016/0012-821x(86)90151-2.

Melcher CL, 1981. Thermoluminescence of meteorites and their orbits. Earth and Planetary Science Letters 52(1): 39-54, DOI 10.1016/0012-821X(81)90206-5.

Poolton NRJ, Ozanyan KB, Wallinga J, Murray AS and Bøtter-Jensen
L, 2002a. Electrons in feldspar II: A consideration of the influence of conduction band-tail states on luminescence processes. Physics and Chemistry of Minerals 29(3): 217-225, DOI 10.1007/s00269001-0218-2.

Poolton NRJ, Wallinga J, Murray AS, Bulur E and Bøtter-Jensen L, 2002 b. Electrons in feldspar I: On the wavefunction of electrons trapped at simple lattice defects. Physics and Chemistry of Minerals 29(3): 210-216, DOI 10.1007/s00269-001-0217-3.

Randall JT and Wilkinson MHF, 1945. Phosphorescence and electron traps. Proceedingsof the Royal Society A 184(999): 365-389, DOI 10.1098/rspa.1945.0024.

Sears DW and Durrani SA, 1980. Thermoluminescence and the terrestrial age of meteorites: Some recent results. Earth and Planetary Science Letters 46(2): 159-166, DOI 10.1016/0012821X(80)90002-3.

Sears DW, Grossman JN, Melcher CL, Ross LM and Mills AA, 1980. Measuring metamorphic history of unequilibrated ordinary chondrites. Nature 287(5785): 791-795, DOI 10.1038/287791a0.

Sears DWG, 1988. Thermoluminescence of meteorites: Shedding light on the cosmos. International Journal of Radiation Applications and Instrumentation. Part D 14(1-2): 5-17, DOI 10.1016/13590189(88)90036-2.

Sears DWG, Sparks MH and Rubin AE, 1984. Chemical and physical studies of type 3 chondrites-III. Chondrules from the Dhajala H3.8 chondrite. Geochimica et Cosmochimica Acta 48(6): 1189-1200, DOI 10.1016/0016-7037(84)90055-3.

Sears DWG and Weeks KS, 1983. Chemical and physical studies of type 3 chondrites - II: Thermoluminescence of sixteen type 3 ordinary chondrites and relationships with oxygen isotopes. Journal of Geophysical Research 88: 301-311, DOI 10.1029/JB088iS01p0B301.

Tyler S and McKeever SWS, 1988. Anomalous fading of thermoluminescence in oligoclase. International Journal of Radiation Applications and Instrumentation. Part D 14(1-2): 149154, DOI 10.1016/1359-0189(88)90056-8.

Visocekas R, 1985. Tunnelling radiative recombination in labradorite: Its association with anomalous fading of thermoluminescence. Nuclear Tracks and Radiation Measurements (1982) 10(4-6): 521529, DOI 10.1016/0735-245X(85)90053-5.

Visocekas R, 2002. Tunnelling in afterglow, its coexistence and interweaving with thermally stimulated luminescence. Radiation Protection Dosimetry 100(1-4): 45-54.

Wintle AG, 1973. Anomalous fading of thermo-luminescence in mineral samples. Nature 245(5421): 143-144, DOI $10.1038 / 245143 \mathrm{a} 0$

Yu Y and Hewins RH, 1998. Transient heating and chondrule formation: Evidence from sodium loss in flash heating simulation experiments. Geochimica et Cosmochimica Acta 62(1): 159-172, DOI 10.1016/s0016-7037(97)00321-9.

Zanda B, 2004. Chondrules. Earth and Planetary Science Letters 224(12): 1-17, DOI 10.1016/j.eps1.2004.05.005. 